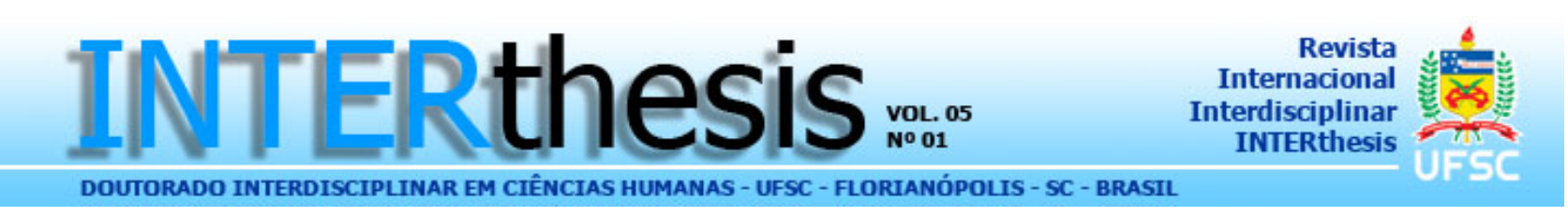

\title{
A POLUIÇÃO ATMOSFÉRICA NO CONTEXTO DA EDUCAÇÃO AMBIENTAL: EXPERIÊNCIAS E DESAFIOS NO TRABALHO INTERDISCIPLINAR EM UMA ESCOLA PRIVADA DE CONTAGEM-MG
}

\begin{abstract}
THE ATMOSPHERIC POLLUTION IN THE CONTEXT OF THE ENVIRONMENTAL EDUCATION: EXPERIENCES AND CHALLENGES IN THE INTERDISCIPLINARY WORK AT A PRIVATE SCHOOL IN CONTAGEM-MG
\end{abstract}

\section{LA CONTAMINACIÓN DEL AIRE EM EL CONTEXTO DE LA EDUCACIÓN AMBIENTAL: EXPERIENCIAS Y DESAFÍOS INTERDISCIPLINARIOS EM EL TRABAJO EM UMA ESCUELA PRIVADA DE CONTAGEM-MG}

\section{Clayton Ângelo Silva Costa ${ }^{1}$}

\section{RESUMO}

O artigo que se apresenta teve como objetivo geral levantar, por meio de entrevistas junto aos docentes envolvidos, quais são os obstáculos da aplicação do projeto interdisciplinar de educação ambiental com ênfase em poluição atmosférica, num colégio da rede privada de ensino do município de Contagem em Minas Gerais. O desenvolvimento foi baseado em procedimentos metodológicos que constam de uma pesquisa bibliográfica e estudo de caso, tendo como sujeitos da pesquisa professores e o coordenador pedagógico que atuam no ensino médio do turno matutino de uma escola situada no bairro centro do município de Contagem em Minas Gerais. As técnicas utilizadas para a coleta de dados foram de entrevistas semi-estrutradas e relatórios derivados de projeto interdisciplinar. Os resultados demonstraram que o desenvolvimento de projetos que tenham como meta a interdisciplinaridade, embora seja um tema de conhecimento geral dos professores, ainda enfrenta uma série de desafios, que vão desde a ausência de infra-estrutura das escolas e apoio geral dos diretores, até questões relacionadas à ausência de um projeto político pedagógico mais completo e que contemple de fato matérias de interesse dos alunos.

Palavras-Chave: Meio ambiente; Poluição; Interdisciplinaridade; Projetos; Educação Ambiental

\section{ABSTRACT}

This paper aims, as its general objective, to raise, by means of interviews with the teachers involved, issues on the obstacles of the application of the interdisciplinary project of environmental education with emphasis on atmospheric pollution, at a private school in

\footnotetext{
${ }^{1}$ Mestre em Ciências Ambientais peça UEMG, graduação em Geografia, Licenciatura Plena e Bacharelado pela PUC-MG, professor da rede estadual e rede privada de educação. E-mail: geoient@gmail.com
} 
Contagem, in Minas Gerais State. The development was based on methodological procedures performed by means of a bibliographical research and case study, having as subject of the research high school teachers and the pedagogic coordinator who work in the morning at a downtown school in the municipal district of Contagem. The techniques used for the collection of data were the semi-structuralized interviews and reports derived from the interdisciplinary project developed. The results have demonstrated that the development of projects that have the interdisciplinary as their goal, even being a theme of the teachers' general knowledge, still faces a series of challenges that go from the absence of schools infrastructure and the directors' general support, to issues related to the absence of a more complete pedagogic political project which, in fact, contemplates subjects of the students' real interest.

Keywords: Environment; Pollution; Interdisciplinary; Projects; Environmental Education

\section{RESUMEN}

El artículo se presenta su objetivo era aumentar la general, a través de entrevistas con los profesores implicados, cuáles son los obstáculos a la aplicación del proyecto interdisciplinario de educación ambiental con énfasis en la contaminación del aire, especialmente en un colegio de Contagem en Minas Gerais. El desarrollo se basa en procedimientos metodológicos han encontrado una búsqueda bibliográfica y estudio de casos, teniendo como sujetos de la investigación docente y los profesores coordinadores que sirven en la escuela secundaria por la mañana a cambio de una escuela ubicada en el distrito centro de la ciudad de Contagem. Las técnicas utilizadas para reunir datos fueron la semi-estrutradas entrevistas e informes del desarrollo de proyecto interdisciplinario desarrollado. Los resultados muestran que el desarrollo de proyectos que tienen como objetivo la interdisciplinario, aunque se trata de una cuestión de conocimientos generales y los profesores todavía se enfrenta a una serie de retos que van desde la falta de infraestructura de las escuelas generales y de apoyo de directores, hasta cuestiones la ausencia de un proyecto político de enseñanza más completa y que abarca en realidad asuntos de interés de los estudiantes.

Palabras-clave: Medio ambiente; La Contaminación; Interdisciplinarios; Proyectos de Educación ambiental

\section{INTRODUÇÃO}

Apesar de todo o progresso alcançado na proteção do meio ambiente durante as últimas décadas, a poluição do ar, da água e da terra ainda representa um dos principais problemas ambientais no mundo.

Concentrações elevadas de poluentes atmosféricos são um risco para a saúde humana, danificam flora e fauna e destroem monumentos históricos e construções modernas. Tais efeitos ocorrem com alta freqüência em aglomerações urbanas, considerando que uma grande quantidade dos mais diversos poluentes está sendo emitida em área relativamente limitada e muitos indivíduos estão sendo afetados, devido à alta densidade populacional.

R. Inter. Interdisc. INTERthesis, Florianópolis, v.5, p. 66-77, jan./jul. 2008. 
No âmbito escolar, o professor de Geografia juntamente como os de Química, Português e História do Ensino Médio de uma dada escola da rede particular de Contagem, elaboraram um projeto interdisciplinar em Educação Ambiental a partir da temática poluição atmosférica, visando desenvolver, uma prática que vincula o educando com a comunidade, valores e atitudes que promovem um comportamento dirigido à transformação superadora dessa realidade, tanto em seus aspectos naturais como sociais, desenvolvendo e verificando no educando as habilidades e atitudes necessárias para dita transformação.

Contudo, durante a execução do projeto, inúmeros obstáculos e controvérsias surgiram e a maioria delas em torno da questão conceitual da "interdisciplinaridade", assunto de grande importância no meio educacional, mas que tem enfrentado sérios problemas para que de fato seja uma realidade nas escolas brasileiras.

Diante do contexto apresentado acima, o objetivo geral deste artigo foi levantar, por meio de entrevistas junto aos docentes envolvidos, quais são os obstáculos da aplicação do projeto interdisciplinar de educação ambiental com ênfase em poluição atmosférica, num colégio particular de Contagem.

\section{MATERIAIS E MÉTODOS}

A técnica metodológica utilizada foi baseada em análises qualitativas, tendo como sujeitos principais os educadores, professores e coordenador pedagógico que atuam no ensino médio do turno matutino de uma escola situada no bairro centro do município de Contagem (RMBH) à Av. Prefeito Gil Diniz.

Os instrumentos utilizados para a coleta de dados foram a observação dos discursos e ações dos educadores durante o processo de elaboração e execução do projeto interdisciplinar em educação ambiental a partir da temática poluição ambiental, os registros de observação ampliado durante o processo de elaboração e execução do projeto, no qual foram anotados os discursos e as ações relevantes dos educadores, bem como comentários pessoais suscitados pelos mesmos e a aplicação de entrevistas semiestruturadas e estruturadas junto aos docentes envolvidos no projeto interdisciplinar.

\section{RESULTADOS E discussão}

R. Inter. Interdisc. INTERthesis, Florianópolis, v.5, p. 66-77, jan./jul. 2008. 


\subsection{Considerações sobre a interdisciplinaridade}

Entre os muitos estudos sobre o assunto, destacam-se trechos dos textos de Hilton Japiassú (1976), Fazenda (1979), Santomé (1998). As obras produzidas por esses autores revelam concepções a respeito da interdisciplinaridade, a começar pela própria definição do termo.

Pode-se considerar que Japiassú (1976), Fazenda (1979) e Santomé (1998) concebem a origem e configuração da interdisciplinaridade de maneira semelhante, optando pela abordagem dos estudos interdisciplinares como uma necessidade de combate à fragmentação do saber.

Um dos primeiros estudos brasileiros sobre a temática da interdisciplinaridade, trata-se da Interdisciplinaridade e patologia do saber e data de 1976.

Nesse texto, parte da tese de doutorado defendida na França por Hilton Japiassú, a interdisciplinaridade é concebida como uma solução para o esfacelamento do saber instaurado pelo positivismo. Já no título da obra, o autor destaca o campo semântico de "doença", a falta de integração dos saberes é considerada uma patologia, um mal a ser execrado. "O número de especializações exageradas e a rapidez do desenvolvimento de cada uma culminam numa fragmentação crescente do horizonte epistemológico [...] o saber em migalhas [é] o produto de uma inteligência esfacelada" (JAPIASSU, 1976, p. 30).

Entre os maiores problemas para superar a fragmentação do saber, Japiassú (1976, p. 61) destaca "a dificuldade de definição de um método adequado e interdisciplinar, já que o método em si implica certa redução do objeto".

Quanto às exigências à interdisciplinaridade, Japiassú (1976, p. 113) destaca "o domínio, por parte dos especialistas, do método da disciplina lecionada, o reconhecimento da parcialidade e relatividade de sua própria disciplina e certa familiaridade com uma disciplina diferente da sua". Para o autor, uma última exigência seria polarizar o trabalho interdisciplinar sobre pesquisas teóricas ou aplicadas. Dessa forma continua descrevendo que: "O conhecimento humano é sintético e global antes de ser analítico e especializado [...] redescobrir ou tematizar essa dimensão sintética de nosso saber é uma exigência fundamental, se quisermos descobrir e desenvolver em nó o sentido da interdisciplinaridade" (JAPIASSU, 1976, p. 113).

R. Inter. Interdisc. INTERthesis, Florianópolis, v.5, p. 66-77, jan./jul. 2008. 
Na mesma linha teórica de Japiassú, Ivani Fazenda é, desde a década de 70, uma das pesquisadoras que mais se dedica ao assunto, tendo escrito diversos livros e orientado muitas pesquisas sobre interdisciplinaridade.

Em seu livro "Integração e Interdisciplinaridade no Ensino Brasileiro: efetividade ou ideologia" surge o pensamento basilar da autora, exposto em textos posteriores: a interdisciplinaridade é, acima de tudo, uma prática. Para Fazenda (1979, p. 08) "a interdisciplinaridade não ensina, nem se aprende, apenas vive-se, exerce-se e, por isso, exige uma nova pedagogia, a da comunicação".

Da mesma forma que Japiassú (1976), Fazenda (1979) acredita grande poder à interdisciplinaridade. Ambos, na verdade, estavam impregnados pelas conclusões divulgadas em 1970, no seminário da OCDE, que estabelecia os seguintes benefícios da interdisciplinaridade: "Meio de conseguir uma melhor formação geral; Meio para atingir uma formação profissional; Incentivo à formação de pesquisas; Condição para uma educação permanente; Superação da dicotomia ensino-pesquisa; Forma de compreender e modificar o mundo" (FAZENDA, 1979, p. 44-48).

O projeto interdisciplinar é mostrado por Fazenda (1979, p. 43) como uma prática viável, apesar das dificuldades: mais do que viável, uma prática essencial para a mudança na forma de conceber e construir o conhecimento. A autora detém-se no ponto de vista pedagógico, não enfatizando fatores históricos que determinam à configuração disciplinar existente.

\subsection{O desenvolvimento do projeto interdisciplinar}

O projeto foi idealizado pelo professor de geografia e, em seguida, apresentado aos educadores que fizeram apenas, algumas considerações a serem introduzidas ao trabalho, como a utilização e/ou inserção de suas disciplinas no contexto interdisciplinar que o projeto necessitava, para ser considerado como tal, ou seja, de uma forma holística.

Os objetivos do projeto fundamentaram-se em trabalhar a consciência ecológica dos alunos a partir da educação ambiental, possibiltando uma reflexão coletiva sobre o assunto. Além disso, visou potencializar a ação da escola na melhoria das condições de vida da comunidade em que se insere, contribuindo para a formação de cidadãos críticos e participativos.

R. Inter. Interdisc. INTERthesis, Florianópolis, v.5, p. 66-77, jan./jul. 2008. 
Durante o segundo semestre os educadores se reuniram algumas vezes para discutirem o desenvolvimento do projeto, fazerem considerações, ponderações, introdução, melhorias e intervenções na medida em que os resultados iam sendo arquitetados.

À medida em que as turmas foram concretizando as etapas ou tarefas juntamente com o auxilio dos docentes, o pesquisador foi realizando suas observações sobre o trabalho específico do professorado do projeto em relação as dificuldades ou desafios de se trabalhar o interdisciplinar a partir da temática da poluição atmosférica na educação ambiental.

Nessa lógica, o professor de geografia juntamente com o de química sugeriram trabalhar com uma temática que estivesse próxima à realidade da comunidade escolar em que o colégio está inserido, então, apresentaram aos demais professores coloboradores do projeto a idéia de colocar como um dos eixos centrais do trabalho o Córrego Ibirapitanga que corre em frente à escola.

Os professores optaram em dividir as tarefas entre dois grupos, um para cada uma das turmas e, cada sala ficaria com a responsabilidade de subdividir outros grupos para executar as tarefas propostas no projeto.Dessa maneira, os educadores acreditam que a participação dos alunos no projeto seria mais efetiva.

O $1^{\circ}$ grupo foi formado pelos alunos do $2^{\circ} \mathrm{M}$, o qual ficou com a responsabilidade de pesquisar à respeito das mudanças ao longo da história e a própria história do córrego e, posteriormente, anexar e confeccionar banner com as informações que o grupo julgar mais importantes. Também, foi de responsabildade desse grupo; coletar amostras de água do córrego e da chuva, analisar no laborátorio as amostras coletadas, e ainda, anexar as faixas confeccionadas pelas duas salas no dia da Feira de Ciências e Tecnologia.

O $2^{\circ}$ grupo, ou seja, os alunos da turma do $2^{\circ} \mathrm{N}$, ficarem responsavéis em formar grupos de estudos com alunos do outro $2^{\circ}$ ano para trocarem informações e repassa-las ao restante da turma, cartografar a área em estudo e redigir frases informativas apresentando propostas de melhoria da qualidade da água e do ar,para posteriormente, serem anexadas em faixas .

A parte prática foi realizada no laborátorio de Química-Física-Biologia do colégio com o acompanhamento dos professores de química e o de geografia. Um outro subgrupo de um dos grupos formados pelas salas encaminharam-se para o laboratório para 
realizarem os experimentos práticos e depois, repassarem os resultados ao restante dos alunos de ambas as salas.

\subsection{Análise dos questionários}

As análises apresentadas abaixo são resultado dos dados colhidos a partir da aplicação de questionários aos sujeitos envolvidos na pesquisa e os discursos indicam sobre: as concepções e práticas de interdisciplinaridade, os conceitos de aprendizagem, o relacionamento entre os professores e alunos e a importância da leitura como conteúdo e estratégia interdisciplinar e que de certa forma demonstram os obstáculos de se trabalhar o interdisciplinar.

Pode-se dizer inicialmente que de uma forma geral, o conceito de interdisciplinaridade que emerge dos discursos dos professores confirmou-se marcado pela polifonia e pelo interdiscurso, pois é atravessado por outros discursos que refletem a voz do senso comum e da academia.

$\mathrm{Na}$ escola pesquisada, o discurso da coordenadora, ao definir o conceito de interdisciplinaridade, reproduz discurso semelhante ao de Ivani Fazenda (1978), voz que representa a academia. Embora não faça referências à autora, a utilização de suas palavras sugere que a coordenadora estabeleceu contato com seus textos.

A esse respeito, Fazenda (1978, p. 26) ensina que "a nível de interdisciplinaridade, ter-se-ia uma relação de reciprocidade, de mutualidade, ou melhor dizendo, um regime de co-propriedade que iria possibilitar o diálogo entre os interessados".

Verificou-se que os discursos dos demais professores estão mais voltados à voz do senso comum e, embora sejam materialmente diferentes, revelam uma concepção de interdisciplinaridade como metodologia de trabalho na qual todos os professores trabalham a seu modo um tema ou assunto comum.

Com relação à leitura de textos que tratam dos temas interdisciplinaridade ou projetos de trabalho e ainda sobre a possibilidade de citar o nome de autores ou texto que tenha lido, os discursos revelam que não foram discutidas mais intensamente, no ambiente escolar, teorias que pudessem ter repercussão na prática pedagógica.

Com relação à existência de projetos envolvendo professores de mais de uma disciplina na escola onde atuam e ainda quais disciplinas geralmente estão mais 
envolvidas, verificou-se que os educadores da escola têm clareza sobre a existência dos projetos interdisciplinares, mas também destacam a importância da afinidade entre os professores para que os projetos aconteçam e a facilidade de relacionar alguns conteúdos.

Quanto questionados se o Projeto Político Pedagógico da escola contempla, prevê projetos envolvendo diversas disciplinas, verifica-se que o projeto pedagógico da escola pesquisada estava disponível e todos os educadores poderiam ter acesso ao mesmo. Mas, a falta de tempo fez com que nenhum dos educadores envolvidos tivesse contato com o projeto pedagógico e, muito menos discutido nas reuniões feitas ao longo do trabalho interdisciplinar.

Foi questionado ainda aos entrevistados como e quando os projetos interdisciplinares são desenvolvidos e aplicados. Importante mencionar que com essa questão, pretendeu-se verificar como e quando ocorrem as ações interdisciplinares no dia-a-dia escolar. Nesse caso, os discursos dos educadores indicam que as orientações são diferentes dependendo dos projetos. A maioria dos educadores faz menção ao processo envolvendo definição de temas fixos e propostos no calendário anual, cronograma e aplicação ao longo do ano.

Quanto questionados se houve ou ainda há obstáculos para a concretização de projetos dessa natureza, verificou-se na pesquisa que os dizeres dos educadores apontam uma série de obstáculos aos projetos interdisciplinares. A coordenadora cita, como principal obstáculo, a falta de envolvimento de alguns docentes. Seu discurso ignora outros problemas que estariam relacionados a essa falta de envolvimento. A professora de Português, mesmo sem saber, contra-argumenta, ao explicar o que considera ser o grande obstáculo? “os projetos são idealizados por 'alguém' e alguns professores não se sentam motivados em participar deles." Esse discurso denuncia uma insatisfação com o papel de executor de projetos alheios.

O discurso do professor de História ressalta o fator tempo como dificultador, o pouco tempo para planejamento, e o longo tempo necessário ao planejamento e desenvolvimento do projeto, o que de certa forma, desestimula os alunos.

\section{CONCLUSÃO}

R. Inter. Interdisc. INTERthesis, Florianópolis, v.5, p. 66-77, jan./jul. 2008. 
O artigo que se apresenta teve como objetivo geral levantar, por meio de entrevistas junto aos docentes envolvidos, quais são os obstáculos da aplicação do projeto interdisciplinar de educação ambiental com ênfase em poluição atmosférica, num colégio particular de Contagem.

Cabe dizer inicialmente que a interdisciplinaridade é um assunto tratado há mais de 30 anos por educadores e estudiosos e esta é tratada como uma necessidade cada vez mais crescente no meio educacional para que seja possível evitar a fragmentação do saber.

Através do desenvolvimento de projetos interdisciplinares é possível integrar o conteúdo de diferentes disciplinas fazendo com que os alunos desenvolvam uma familiaridade com determinados temas e consigam relaciona-lo com o cotidiano e com a realidade vivida nas diferentes fases do aprendizado, pois possibilita aliar pesquisas teóricas e aplicadas à pratica necessária para o desenvolvimento da capacidade de interpretação.

Contudo, verificou-se no desenvolvimento deste trabalho que o desenvolvimento de práticas que envolvam a interdisciplinaridade ainda enfrenta uma série de desafios no sistema educacional brasileiro e estes estão relacionados à dificuldades de propor métodos eficazes, falta de conhecimento e domínio dos professores dos assuntos específicos a serem tratados, falta de incentivo dos gestores escolares e ainda a resistência dos alunos em participar de projetos dessa natureza.

Visando propor uma análise baseada em resultados práticos para que o tema fosse abordado de forma completa, foi também proposto realizar uma pesquisa qualitativa junto aos docentes, analisando os resultados coletados na entrevistas realizadas.

Para que tal processo fosse realizado, tomou-se como base um projeto interdisciplinar desenvolvido pelos professores em conjunto com o autor e pesquisador dessa dissertação.

O projeto interdisciplinar tinha como tema central a poluição ambiental e foi realizado utilizando amostras de água colhidas em um córrego denominado Córrego lbirapitanga. Para que a interdisciplinaridade fosse a base do trabalho, participaram de seu desenvolvimento os professores de Português, História, Geografia e Química, além da coordenação geral da escola e os passos de realização do projeto foram detalhados no desenvolvimento deste trabalho.

R. Inter. Interdisc. INTERthesis, Florianópolis, v.5, p. 66-77, jan./jul. 2008. 
Com relação à verificação da opinião dos professores sobre o desenvolvimento do projeto, assim como os principais obstáculos enfrentados para que a interdisciplinaridade seja uma realidade nas escolas brasileiras identificou-se, em primeiro lugar que embora os professores e a coordenação, tenham uma noção baseada no senso comum sobre o que vem a ser o termo, não conhecem detalhadamente os conceitos de interdisciplinaridade o que por si só já se apresenta como um grande obstáculo ao desenvolvimento de projetos dessa natureza.

Identificou-se que a falta de conhecimento dos professores sobre o que vem a ser interdisciplinaridade é decorrente de uma série de fatores. O primeiro deles é a ausência de motivação para a busca externa de conhecimentos, pois a pesquisa realizada demonstra que poucos são os professores que buscaram leituras sobre o tema com o objetivo de conhecer detalhadamente o assunto e suas práticas em sala de aula.

Além disso, embora a escola pesquisada já tenha desenvolvido projetos de interdisciplinaridade, nota-se que os professores pesquisados pouco se envolveram, alguns por não terem sido chamados, outros por não terem afinidade com os demais professores.

Destaca-se então que a ocorrência de projetos interdisciplinares não está diretamente relacionada ao projeto pedagógico da escola, mas à maior disponibilidade de alguns professores e à maior facilidade em relacionar alguns temas e tal situação também se coloca como um grande obstáculo para que de fato projetos de interdisciplinaridade sejam uma realidade na escola pesquisada.

De maneira geral, verificou-se que a escola se mostra aberta para a realização e desenvolvimento de projetos de interdisciplinaridade, mas falta motivação, integração e conhecimento por parte dos professores para que de fato estes sejam desenvolvidos com maior freqüência e que acima de tudo façam parte do Projeto Político Pedagógico da escola.

Nesse caso, é necessário, prioritariamente, que todos os professores procurem capacitação visando obter maior conhecimento e consciência sobre a sua responsabilidade no processo ensino / aprendizagem e sobre sua participação no desenvolvimento de projetos de interdisciplinaridade.

Pode-se concluir que apesar de enfrentar ainda uma série de desafios e dificuldades, o desenvolvimento de projetos de interdisciplinaridade nas escolas 
brasileiras é uma prática viável, mas exige, acima de tudo, uma nova pedagogia que tenha como base o estreitamento da comunicação e dos laços entre gestores escolares, professores e alunos. É preciso que todos estejam integrados em torno de objetivos em comuns e acima de tudo é preciso buscar continuadamente conhecimentos para que o desenvolvimento dos projetos sejam criativos, motivadores e de fato abordem conteúdos de interesse dos alunos possibilitando um aprendizado dinâmico e eficaz.

\section{REFERÊNCIAS}

FAZENDA, I. C. A. Integração e interdisciplinaridade: uma analise da legislação do ensino brasileiro de 1961 a 1977. 1978. 111 f. Dissertação (Mestrado em Educação). Pontifícia Universidade Católica. São Paulo, 1978.

FAZENDA, I. C. A. Integração e interdisciplinaridade no ensino brasileiro: efetividade ou ideologia. São Paulo: Loyola, 1979.

FAZENDA, I. C. A. Práticas interdisciplinares na escola. São Paulo: Cortez, 1991a.

FAZENDA, I. C. A. Interdisciplinaridade: um projeto em parceria. São Paulo: Loyola, 1991b.

FAZENDA, I. C. A.Interdisciplinaridade: história, teoria e pesquisa. Campinas: Papirus, 1998.

FAZENDA, I. C. A. (org) Didática e interdisciplinaridade. $2^{\circ}$ ed. São Paulo: Papirus, 1998.

FAZENDA, I. C. A. (org) Interdisciplinaridade: dicionário em construção. 2. ed. São Paulo: Cortez, 2002.

FAZENDA, I. C. A. Interdisciplinaridade: qual o sentido? São Paulo: Paulus, 2003.

FREIRE, P. Pedagogia da Autonomia: saberes necessários à prática educativa. 27. ed. São Paulo: Paz e Terra, 2003.

FREITAS, M. A. de. Interdisciplinaridade e multimeios: um estudo de caso. 1996. $120 \mathrm{f}$.

Dissertação (Mestrado em Educação) - Faculdade de Educação, Universidade de São Paulo, São Paulo, 1996.

GADOTTI, M. Pedagogia da Práxis. 3. ed. São Paulo: Cortez: Instituto Paulo Freire, 2001.

GARCIA, R. O conhecimento em construção: das formulações de Jean Piaget à teoria de sistemas complexos. Porto Alegre: Artmed, 2002.

JAPIASSU, H Interdisciplinaridade e patologia do saber. Rio de Janeiro: Imago, 1976.

MORIN, E. O Método I, a natureza da natureza. Portugal: Publicações Europa-América Ltda., 1997(a).

R. Inter. Interdisc. INTERthesis, Florianópolis, v.5, p. 66-77, jan./jul. 2008. 
MORIN, E. Aqui é onde eu moro, aqui nós vivemos - escritos para conhecer, pensar e praticar o município educador sustentável.Brasília: Ministério do Meio Ambiente, 2005.

SANTOMÉ, J. T. Globalização e interdisciplinaridade: o currículo integrado. $1^{\circ}$ reimpressão revista. Tradução Cláudia Shilling. Porto Alegre: Artmed, 1998. 275 p.

Artigo recebido em 11 de abril de 2008. Artigo aceito em 24 de junho de 2008.

R. Inter. Interdisc. INTERthesis, Florianópolis, v.5, p. 66-77, jan./jul. 2008. 